\title{
"Isso é política, meu!" \\ Socialização militante e institucionalização dos movimentos sociais
}

Rosangela Carrilo M oreno* eAna M aria F. Almeida**

Resumo: Como secria uma associação militante? Q ueelementos e/ ou processos são necessários para que indivíduos ajam como um grupo para criar uma organização destinada a atuar no espaço político? Esta questão foi discutida numa pesquisa que focalizou um grupo dejovens rappersnegrosque fundou uma associação no final dosanos 1990 em C ampinas, SP. Por meio delongas, repetidas entrevistaseobservações dealguns dos seus encontrosepráticas, mostramos que a associação foi o resultado de um processo de aprendizagem por que passaram osjovens, ao longo de um contato estreito com políticos profissionais mais vel hos emais experientes. $N$ esse processo eles aprenderam como um movimento de protesto deveria se articular para influenciar o governo. Aprenderam também certas técnicas demobilização quelhes permitiram ser respeitados e construir apoios em outros segmentos de ativismo partidário esindical. As ações da associação deram concretude evisibilidadeà idéia deque havia um "movimento hip hop" na cidade. Em 2001, ao final deuma longa negociação, seus membros obtiveram o apoio da prefeitura municipal da cidade, assumida pelo PT, para a criação da C asa do H ip H op de Campinas, ondeelesforam empregados para desenvolver atividades artísticas e políticas.

Palavras-chave: socialização política; militância.

"That's politics, man!"

Militant socialization and the instutitionalization of social movements

Abstract: $\mathrm{H}$ ow aremilitant associationscreated?W hich elementsand/or processesallow individuals to act as a group and createan organization aimed at interfering in the political sphere?Welook into this question by studying a group of young black rappers who created their association in the late 1990's in Campinas, SP. Through long, repeated interviews and the observation of some of their encounters and practices, weshow that the association was made possibleby a learning process experienced by the rappers through their contact with older and experienced politicians. In the process, they learned how to organize a political movement in order to influencegovernment policies. They al so learned a number of "activist techniques" that helped them to be respected and to find support in other segments of party and syndicate activism.

\footnotetext{
* Doutoranda em Educação e membro do Grupo de Estudos sobre Instituição Escolar e Organizações Familiares (Focus) da Faculdade de Educação da Unicamp. Campinas, SP, Brasil. rocarrilo@yahoo.com.br

* Professora da Faculdade de Educação da Unicamp e co-coordenadora do Focus. Campinas, SP, Brasil.aalmeida@unicamp.br
} 
Through the association, the rappers made the Campinas hip hop movement concrete and visible and, in 2001, they obtained support from the Partido dos Trabalhadores city administration, for the creation of a $\mathrm{H}$ ouse of $\mathrm{H}$ ip $\mathrm{H}$ op, a center where they were employed to develop artistic and political activities.

Key words: political socialization; activism.

Um dos problemas recorrentes nos estudos sobre militantismo é compreender como se cria uma associação militante: que elementos e/ou processos são necessários para que um grupo de indivíduos aja em comum acordo e chegue a criar uma organização destinada a atuar no espaço político?

Parte da literatura que se dedicou a pensar esse problema argumenta que a criação de associações desse tipo, isto é, associações que se caracterizam como grupos de interesses, é decorrência de certas transformações estruturais que, afetando as vidas das pessoas, faria aumentar o grau de frustração dessas. 0 surgimento das associações seria, assim, uma conseqüência mais ou menos natural da difusão desse estado de espírito pela população, o que provocaria, por sua vez, a criação de mais associações ${ }^{1}$.

Essa maneira de pensar o problema deixa de lado pelo menos um aspecto que nos parece crucial e que diz respeito ao trabalho de organização necessário para a criação de uma associação, forma de aglutinação que materializa a existência de um grupo "vontade e representação", na maneira pensada por Pierre Bourdieu no seu trabalho sobre o Espaço social e gênese das dasses (2000a , p. 159-160) e desenvolvida nos estudos realizados por Michel Offerlé (1998; 1999; 2002).

Esse aspecto é a porta de entrada para uma indagação sobre o que torna possível a institucionalização dos movimentos sociais, isto é, sobre os processos de articulação da ação de indivíduos no interior de um grupo determinado, que levam à definição do seu papel, de suas regras de funcionamento ou, talvez mais precisamente, de uma identidade passível de ser reconhecida tanto pelos próprios membros, quanto por aqueles que estão fora do grupo e, entre estes últimos, particularmente por aqueles contra os quais se posicionam.

$\mathrm{N}$ este artigo, nós discutimos essa questão a partir de uma pesquisa que focalizou um grupo de jovens rappers que se identificam como negros, muito atuante na origem do "movimento hip hop" de Campinas, onde fundaram uma associação em meados dos anos 1990.

\footnotetext{
I. Para Truman (195I), no muito citado estudo Political process, isso funcionaria em ciclos ou "ondas": "Quando uma associação é formada [...], no desempenho da sua função ela pode perturbar o equilíbrio de outros grupos. [...] Estes, por sua vez, vão provavelmente criar associações para corrigir [essas] perturbações. A formação de associações, assim, tende a ocorrer em ondas" (Truman, 195।, p. 59). Ver também McFarland (|99|).
} 


\section{Oempreendedorismo do político profissional}

Para compreender a criação da associação, é preciso, em primeiro lugar, perceber que o simples fato de vários indivíduos compartilharem um mesmo objetivo não é suficiente para levá-los a dar os passos necessários para institucionalizar a luta por esse objetivo, transformando-o em base para a criação de uma associação.

É certo que há, entre eles, uma identidade de posição social: (i) são negros; (ii) são oriundos de grupos economicamente desfavorecidos, mas que viveram uma pequena ascensão social; (iii) receberam uma educação disciplinada, centrada numa moral baseada na dignidade, na honestidade e no trabalho; (iv) vivenciaram um contato precoce com um universo musical específico; (v) frustraram-se na sua dedicação à escola. É razoável supor que tudo isso, junto com suas próprias percepções sobre o processo, ajude a explicar tanto a proximidade com 0 rap - e, principalmente, o rap que se estrutura como protesto e denúncia social - , quanto o fato de terem considerado possível e desejável investir numa carreira artística como uma saída para o que percebiam como uma falta de oportunidades de inserção social que respondessem a suas expectativas².

Além disso, é certo que vivenciaram, no interior de uma densa teia de sociabilidade, uma posição dominada no circuito de produção e divulgação do rap em Campinas; é possível supor que isso Ihes tenha dado a possibilidade de indignar-se em grupo e de engajar-se, também em grupo, na busca por meios de romper o bloqueio dos rappers já estabelecidos.

$\mathrm{N} o$ entanto, o estudo do processo mostra que esse passo fundamental não poderia ter sido dado sem o trabal ho e o investimento intensivo de um político profissional, vereador pelo PT no período em questão, na formação militante dos jovens ena estruturação jurídica da associação. Também não poderia ter sido dado sem um investimento específico dos jovens na sua própria formação política, uma social ização militante bastante concreta e que implicou numa mudança cognitiva importante relativa à visão que tinham do mundo e de si mesmos.

Em 1997, o encontro regular desse grupo de jovens nas praças públicas do centro da cidade, para trocar informações, partilhar experiências sobre o universo do rap e pensar em maneiras de produzir seus próprios eventos, acabou criando um movimento diferente nos finais de semana, que não tardou a ser notado.

N essa época, um vereador recém-eleito pelo Partido dos Trabalhadores (PT) estabeleceu um contato com eles com o objetivo de construir um diálogo que visava investir na sua aproximação, tanto com certos setores do movimento

2. Para uma discussão sobre a relação entre socialização e engajamento político, ver Moreno (2007) e Moreno e Almeida (2009). 
negro, quanto com os movimentos voltados para a juventude popular. Esse vereador havia iniciado sua militância no Sindicato dos Eletricitários de C ampinas, em 1986. Filiou-se ao PT em 1989 e atuou de forma contínua na área dos chamados movimentos populares, principalmente movimentos de moradores de bairro, e na ação sindical, sempre ligada ao Sindicato dos Eletricitários. Elegeu-se vereador na cidade em 1996 e tomou posse em 19973. Entre outras atividades desenvolvidas ao longo desse período de aproximação, o vereador, levado por uma militante, foi até um desses eventos de rap organizados por aqueles jovens, tendo sido apresentado a alguns deles e tomado contato com 0 trabalho desenvolvido pelos grupos a eles ligados. A identificação, segundo relato dos envolvidos, parece ter sido imediata. Aproximando-se de três desses jovens que ocupavam na época uma posição proeminente na organização dos eventos, ele propôs dar suporte material aos grupos de rap a que eles estavam associados e dos quais se diziam porta-vozes, para que pudessem organizar eventos nos bairros de periferia da cidade.

I sso passou a acontecer de forma sistemática a partir daí, concretizando uma aliança não muito surpreendente, se notarmos que ela pode ser vista como 0 encontro entre posições sociais e objetivos homólogos. 0 vereador, assim como a maioria dos jovens interessados em inserir-se no campo de produção e divulgação de rap da cidade, é negro, de origem social modesta, atuou em uma atividade profissional de pouco prestígio (técnico eletricitário), além de ocupar, no campo da política, uma posição análoga à ocupada pelos jovens no campo cultural. Se, no campo da cultura, esses jovens ocupavam uma posição que não Ihes permitia se impor diante dos grupos de rappers já estabelecidos na cidade, na política, o vereador participava de uma corrente petista que só existe na cidade de Campinas, ocupando, portanto, uma posição dominada no interior do partido à época. N essa situação, tanto um quanto os outros buscavam alianças para fazer frente às lutas de concorrência que enfrentavam.

Essa homologia foi claramente captada pelos jovens:

Eu reconheço queo trabalho do mandato deleera muito bom, a legisação queeleaprovou, eeleera um cara quecurtia o movimen-

3. O mandato desse vereador foi marcado por iniciativas ligadas à questão racial, como o demonstra a lista dos projetos de lei por ele apresentados no período: I. instituição do Programa de Aconselhamento Genético Preventivo e Assistência Médica Integral às pessoas portadoras do traço falciforme e com anemia; 2. inclusão no currículo da rede municipal de ensino, inclusive no Supletivo, na disciplina de história, de matéria relativa ao Estudo do Negro na formação sociocultural brasileira; 3. lei que exige pluralidade ético-racial para as propagandas da administração direta ou indireta do município; 4. instituição do Dia Nacional da Consciência Negra no dia 20 de novembro e sua definição como feriado municipal. (dados extraídos da página < http:// www.ptcampinas.org.br/parlamentares/parlamentares_tiao.asp>, acessada em junho de 2006). 
to. Tem fotosdeledecabelo black power quando deera patrulhero eàsvezestinha unseventos, rolava um som funk eeleentrava na roda edançava. Aí a galera percebeu quea relação quee leestabele ceu com a gentenão foi uma relação dequerer seaproveitar da gente politicamente, elerealmentetinha identidadecom a gente Então foi natural assim, a gente foi seaproximando ea relação pessoal veio antes da relação política, aí isso foi muito legal. (Alessandro, entrevista de pesquisa, C ampinas, dezembro, 2005).

As primeiras atividades que esse grupo de jovens desenvolveu com apoio do vereador foram eventos em bairros da periferia da cidade, utilizando espaços de associações de bairros e ON Gs, para ajudar no levantamento de fundos para instituições como abrigos de crianças ou idosos, arrecadando, como valor de entrada, alimentos ou agasalhos. 0 apoio do vereador concretizava-se pela viabilização de contatos com as próprias associações e 0 N Gs e pela ajuda financeira, tanto para 0 aluguel de equipamento de som e transporte quanto para, e talvez o mais importante, a divulgação dos eventos. M ovidos pelo empreendedorismo artístico de uns e político do outro, os rappers e o vereador logo decidiram que os eventos deviam ter um nome, um rótulo, que os diferenciasse tanto no espaço de divulgação do rap quanto no espaço político. 0 nome forjado, Rota do Rap - Periferia tem Solução, expressa justamente esse duplo vínculo e permitia a identificação imediata do grupo, com o benefício óbvio de associá-los a algo mais perene e institucional.

Com isso, os jovens reuniram mais recursos para pleitear sua inserção na cena hip hop da cidade. M ovidos pelas lutas de concorrência que estruturam esse espaço, os jovens passam a perceber-se e a apresentar-se como produtores do rap com fins sociais, esforçando-se para atribuir uma conotação mais nobre ou mais legítima à maneira como atuavam no hip hop, se comparada àquela associada aos que estavam investindo na busca de uma inserção no mercado fonográfico - em geral, produtores de eventos já estabelecidos, cujas iniciativas eram percebidas e, como tal, rotuladas como situadas apenas no espaço do entretenimento. M iro relata:

[...] a gentetinha um trabalho diferencial detodo mundo, porque a nossa praia era organizar evento, masera organizar deverdade, assi $m$, não era fazer um evento echamar um montedegentepara tocar. [...] $\mathrm{N}$ a verdade, quando a gente começou, a gentefalava assim: "Vamosfazer um evento na quebrada detal fulano, vamos fazer um evento na quebrada detal fulano." E a coisa começou a tomar corpo, eaí a gentefalou: "N ão, vamosfazer evento beneficentepara instituiç̧ão tal, $0 \mathrm{~N} \mathrm{G}$ tal, a casa dosai déticosetá pre cisando deajuda, vamoslá." [...] M as, em contrapartida, unia o útil ao agradável, só queera tudo inconsciente A consciência nossa 
era vamostocar, como todo mundo quevinha para o movimento era para dançar, para grafitar e cantar, a gente queria cantar. Como não tinha espaço, o espaç̧o quea gentearrumava era esse $A$ ON G cedia um palco, arrumava aparelhagem, a genteorganizava 0 evento efazia. (M iro, entrevista de pesquisa, C ampinas, maio 2006).

Ainda em 1997, o vereador propôs aos jovens a organização de um evento mais ambicioso, a que deram o nome de Rap em Trânsito e que, a partir daí, passou a acontecer anualmente até 2004, sob organização desses jovens.

Levando adiante a idéia do duplo vínculo, isto é, a ligação com o espaço artístico e fonográfico e a ligação com o espaço político, o evento tinha duas frentes. Uma delas consistia nos shows propriamente ditos, nos quais se apresentavam grupos de Campinas e de outras cidades. D enominada "frente cultural", consistia em shows e oficinas montadas pelo próprio grupo e por personalidades do movimento hip hop com maior visibilidade no circuito São Paulo-Rio. Isso era motivado fundamentalmente pelo intuito de articular os jovens ao hip hop mais dominante. Assim, para o primeiro Rap em Trânsito foram convidados grupos como Thaíde e DJ Hum, Sistema N egro e 4 Bases.

Paral elamente a isso, desenvolvia-se a outra frente: uma série de debates de questões consideradas importantes para o universo dos jovens ou do hip hop. Assim, por exemplo, o tema central do primeiro evento foi Racismo eViolência ${ }^{4}$.

A organização do Rap em Trânsito representou, para o vereador, um duplo investimento. Por um lado, concorria para a formação política desses jovens, especialmente em relação à questão racial, estreitando a dependência deles em relação ao espaço político, enquanto, por outro lado, contribuía para fortalecer a posição do vereador no próprio espaço político, solidificando sua associação com as questões da juventude e da discriminação. Trata-se aí de uma ligação que ele estava bastante interessado em cultivar, tendo chegado a substituir um assessor, membro do movimento negro, por uma jovem do grupo que era também associada ao movimento negro.

No que diz respeito aos jovens, a aliança com o vereador garantiu também a efetivação de contatos com militantes do movimento sindical, do movimento negro e do Partido dos Trabalhadores, socializando-os no universo da política profissional. As reuniões do grupo, por exemplo, passaram a acontecer na sede do Sindicato dos M etalúrgicos da cidade.

4. Nos anos seguintes as temáticas do evento foram: A origem do movimento hip hop da cidade de Campinas (1998), 500 anos de Brasil (1999), Violência. Já sofreu? (2000), A velha escola do hip hop (200 I), O que é o hip hop e as faces da violência (2002), Autonomia e autogestão (2003) e Propriedade intelectual e a influência no movimento hip hop (2004). 
Por meio do contato prolongado e cada vez mais estreito com sindicalistas e militantes partidários, os jovens puderam desenvolver habilidades e competências fundamentais, apropriando-se de um vocabulário específico, de técnicas de participação e organização de reuniões e debates, redação de panfletos, entre outros. Esse efeito da convivência com os sindicalistas é algo de que eles têm bastante consciência, como conta um dos rappers.

A gentechegava maiscedona reunião, não tinha nada para fazer, então tinha um montedeboletim para ler, vocêficava lendo aquilo ali e pá, lia, lia, lia, trabalhador, você, não sei o que e aquilo começou a despertar muita coisa em mim, aquelesboletins. Porque àsvezespara algumaspessoasaquilo éuma coisa boba, masa gente lia... não tinha nada para fazer. (M iro, entrevista de pesquisa, Campinas, maio 2006)

Esse ponto é crucial para compreender as transformações por que pôde passar o grupo de jovens, já que essa socialização foi o que permitiu, em grande parte, uma modificação no próprio caráter "social" do agrupamento que, progressivamente, foi se caracterizando de uma outra maneira, uma maneira que valorizava o debate político, a discussão de questões políticas, a formação política. Pouco a pouco se articulavam os elementos necessários para que os jovens se percebessem como, além de aspirantes a rappers, parte de um movimento social:

Q uando a gentecomeçou essa organização degruposderap era tudo inconsciente. É, não tem nada a ver com política. Eu odiava que falava para mim: "N ão, vocênão sè oque, tem quever o negócio, coisa de política, participar de reunião". Eu falava: "Ah, moço, vocêestá metirando, ô louco. Eu? Partido? Reunião? Pára com isso." Aí o cara falou assim para mim: "Pô, vocêjá parou para pensar quevocêfaz política no dia-a-dia, vocêorganiza reunião, vocêconvoca, vocêpuxa lá o pessoal, organiza evento. Isso épolítica." Eu falè: "N ão! Vocêestá ficando louco." Aí o cara falou: "Isso épolítica, meu, vocêprecisa abrir o olho para o quevocêestá fazendo, vocêetá falando, vocêetá sendo contradi tório." Eu fui começar a perceber queera verdade, a gentejá fazia só queera muito incons ciente, ea gentenão queria acreditar queera. (M iro, entrevistade pesquisa, Campinas, maio 2006).

Se, inicialmente, os encontros entre rappers eram conversas informais sobre suas afinidades, suas lutas cotidianas, seus interesses e sonhos com relação à afirmação como artista do hip hop, esse contato com a militância institucionalizada levou-os a, progressivamente, construir um discurso e uma forma de interação, como conta Alessandro: 


\begin{abstract}
A gente começou a desenvolver uma dinâmica de movimento social mesmo, marxista. Então asreuniõestinham inscrição para falar. Lógico quea gentenão era tão burocrático quenem àsvezeso movimento é, então não ficava marcando o tempo, não tinha aquela questão de ordem, questão deencaminhamento, isso não tinha. As reuniões eram em círculo, todo mundo falava, tinha votação senão tivesseacordo. (Entrevista depesquisa, C ampinas, junho 2006)
\end{abstract}

0 papel dos políticos profissionais na conformação de um movimento hip hop brasileiro não se restringiu a Campinas. Com relação a São Paulo, Guasco (2001, p. 27), ao tratar do grupo M ovimento H ip H op O rganizado (M H 20 ), relata a participação dos jovens dessa organização no gabinete de um vereador petista ou como funcionários ou como "negociadores" entre 0 rap e partidos como PT e o Partido Comunista do Brasil (PCdoB), citando, como exemplo, o caso do empresário do grupo de rap Racionais, conhecido nacionalmente. 0 M H 20, que expandiu sua organização para outras regiões do país, manteve uma estreita ligação entre o hip hop e os partidos de esquerda no campo da política profissional (Félix, 2000). N o C eará, os participantes do M H 20 aproximaram-se de partidos políticos, como o Partido da Revolução dos Trabalhadores (PART) e o Partido Socialista dos Trabal hadores U nificados (PSTU), ou de agrupamentos como Juventude Vermelha (Félix, 2000, p.295).

D a mesma maneira, outros autores que se dedicaram ao estudo dos chamados "novos movimentos sociais" que se tornaram visíveis nas últimas décadas, têm notado o quanto sua institucionalização é tributária da intervenção de antigos militantes sindicais, no caso da França (Sawicki, 2003), ou decorre da luta por direitos civis ou contra a guerra do Vietnam, no caso dos Estados Unidos (Berry, 1993).

Esses antecedentes contribuíram para que os jovens de Campinas percebessem a aliança entre hip hop e política partidária não apenas como viável, mas também como de praxe.

Trata-se aí de uma aliança que parece também se apoiar numa homologia, já que, no campo da política, o PT, assim como alguns outros partidos que se apresentam mais à esquerda no espectro político, oferece, como um dos seus produtos políticos, referências identitárias associadas aos trabalhadores, aos pobres, aos grupos étnicos minoritários que vão ao encontro das identificações acionadas pelos membros do hip hop. 
A associação como empresa de representação

Em 1998, um ano após os primeiros contatos com o vereador, foi fundada a associação de rappers que recebeu 0 nome de Posse Rima \& $\mathrm{Cia}^{5}$. A institucionalização representou a transformação de um grupo latente em grupo de fato (O fferlé, 1998, p. 39-81) e foi acompanhada por procedimentos que demarcaram a passagem de um espaço de sociabilidade livre de obrigações para o desenvolvimento de atividades reguladas e regradas pelo próprio grupo.

A formação da posse marcou um duplo movimento. De um lado, significou a institucionalização do agrupamento, que especializou suas tarefas, definiu papéis no interior do grupo e regras de funcionamento. De outro lado, marcou a ampliação do número de membros e de agregados, um efeito da realização rotineira de eventos bastante divulgados nos quais se dava, a grupos poucos conhecidos, a oportunidade de tocar. H ouve um investimento consciente, tanto por parte dos jovens, quanto por parte do vereador, na ampliação do escopo da associação. Por exemplo, em 1998, o evento Rap em Trânsito incorporou os dançarinos de break e grafiteiros no debate e na realização de oficinas, além de um grupo de moças que, embora não praticantes das modalidades de hip hop citadas, davam um importante suporte intelectual e logístico ao grupo ${ }^{6}$.

Para os jovens, o aumento do número de participantes interessava porque fazia crescer o seu prestígio como grupo, tanto no espaço de produção e divulgação do hip hop, quanto no espaço político, isto é, diante do movimento negro, dos sindicatos e do PT, em que certos dirigentes acompanhavam de perto e atentamente 0 crescimento do grupo.

Para o vereador, a aglutinação de jovens do break e do grafite a essa associação era algo que aparecia como 0 caminho natural a ser seguido por qualquer grupo militante que quisesse se fortalecer e, claro, implicava um aumento no impacto de sua associação com a juventude dos bairros pobres da cidade.

Esse processo de aglutinação foi beneficiado também pelo fato de que 0 break, o grafite e o rap já eram percebidos, pelos próprios produtores e pela

5. Nas palavras de uma participante desse universo que veio a desenvolver uma dissertação de mestrado sobre mulheres no hip hop, "Posse é uma organização de formação autônoma que concentra, no caso de Campinas, um número variado de grupos de rap que buscam ações coletivas mais estruturadas dentro de seu território." (Lima, 2005, p. 6).

6. Por volta do ano 2000 , depois de mais de cinco anos de trabalho militante conjunto e inspirado pelas discussões em andamento na cena hip hop norte-americana, o grupo passou a identificar o trabalho desenvolvido por essas moças como o 5o. elemento do hip hop, o "conhecimento". O grupo de moças seria, nessa visão, o responsável por guardar o "conhecimento" do hip hop. No estado atual de formulação da questão, os outros quatro elementos do hip hop são: o DJ (diskjockey), o MC (mestre de cerimônias), o break e o grafite. 
mídia, como segmentos do movimento hip hop ${ }^{7}$, tendo obtido bastante visibilidade certos espaços, como A Casa de C ultura de $D$ iadema e a posse $H$ ausa de São Bernardo do Campo, que desenvolviam atividades com todos os segmentos do hip hop (Andrade, 1996). Foi nesse momento, então, que os jovens, dedicados até então ao rap, passaram a perceber-se como ativistas do movimento hip hop, assumindo e desenvolvendo o trabalho de enunciação necessário à própria constituição do grupo, produzindo e formatando seus interesses.

Para os dançarinos de break, assim como para os grafiteiros, por sua vez, estabelecer contato com a Posse Rima \& Cia e com o vereador significava envolver-se nos eventos organizados por estes, ganhando assim alguma estabilidade e muito maior visibilidade.

Várias mudanças aconteceram nesse processo. Se, inicialmente, o número de pessoas era pequeno, com o tempo os encontros passaram a reunir cerca de 70 grupos de rap, ou seja, aproximadamente 200 jovens da cidade e da região. As reuniões que, no início, aconteciam nas ruas e nas praças, passaram a dar-se em salas de sindicatos, no gabinete do vereador ou mesmo em salas de edifícios oficiais, como o Palácio dos Azulejos, que abriga o M useu da I magem e Som da cidade. As conversas livres e informais foram substituídas por reuniões com pauta, inscrição de fala, votação, registro em ata.

Como desde o princípio o grupo se opôs aos empresários que dominavam 0 circuito de divulgação do rap, os porta-vozes da associação apresentavam seus esforços como uma luta para criar um espaço democrático do qual qualquer grupo de rap pudesse participar. No entanto, essa participação era sujeita a regras e acordos efetivados no interior do grupo. Requeria-se, por exemplo, a participação dos membros em um número mínimo de reuniões para que seu grupo pudesse participar do sorteio que definiria os grupos que se apresentariam em cada evento.

Essa estruturação das relações foi concretizada pela produção de um estatuto que organizava, segundo os princípios do direito brasileiro, as regras de funcionamento do grupo. Esse estatuto, registrado posteriormente em cartório, foi produzido com a ajuda de um advogado indicado pelo vereador.

No estatuto concretiza-se a divisão do trabalho entre os jovens, o que já acontecia informalmente. Preocupados em não construir posições hierárquicas no grupo, os jovens decidem montar a associação com uma coordenação

7. Ver Andrade (1996; 1999), Herschmann (1997). Segundo a organização Zulu Nation, que tem o hip hop como uma das frentes de intervenção, Afrika Bambaataa, o fundador da organização, reuniu esses elementos sob tal denominação e passou a comemorar o aniversário do hip hop em 12 de novembro de 1974. (Ver Improviso. Informativo do Movimento Hip Hop. Editorial. n. I, novembro de 2003, Campinas). 
colegiada, ou seja, sem presidente. Com isso, segundo eles, pretendiam impedir a personificação de um líder. 0 que a formatação burocrática não pôde impedir, no entanto, inclusive porque já era uma de suas conseqüências, foi a própria divisão estabelecida no dia-a-dia do trabalho militante.

Como mostra Guillot (1998), a divisão do trabalho militante, em geral altamente hierarquizada no interior dos grupamentos, está presente nas organizações políticas de diferentes gêneros. Esse autor avança a hipótese de que a própria organização de militantes reproduziria a divisão do mundo social. 0 estudo das características sociais dos jovens que lograram ocupar essa posição mostra que há, de fato, uma homologia entre posição social e posição no interior do grupo.

Assim, nesse processo de mutação da ação militante, outros tipos de capital militante passam a ser valorizados, como a capacidade de organização, de definir e seguir regras, de saber falar da maneira mais apropriada para mobilizar e aglutinar pessoas, de saber escrever projetos, demandas, panfletos. N ão é surpresa, portanto, constatar que a "coordenação" da associação acabou sendo assumida pelos jovens ou mais escolarizados ou mais "escolados", isto é, aqueles cujos recursos familiares ou políticos adquiridos ao longo da vida permitiram desenvolver anteriormente habilidades, especialmente a oratória, que lhes garantia destaque e prestígio diante dos demais rappers, praticantes do break e do grafite.

Embora os entrevistados insistissem, nas entrevistas, em afirmar ser a coordenação uma relação bastante informal, eles também indicaram, com profusão de exemplos, que estava reservada a esses coordenadores a efetivação dos contatos com os políticos e com as associações, constituindo-se os coordenadores, de fato, progressivamente, em porta-vozes autorizados da massa de praticantes do hip hop, que se tornava cada vez maior e cada vez mais reduzida à posição de performers e, claro, de prova da força da associação.

Com esse modo de organização da associação, a divisão do trabal ho acabou operando uma separação e uma distinção interna. $\mathrm{H}$ avia aqueles militantes que participavam da associação para tocar, panfletar ou emprestar equipamentos de som e aqueles outros que organizavam a associação, escrevendo os panfletos; entrando em contato com a assessoria do gabinete do vereador ou com os sindicalistas para levantar recursos financeiros e materiais; assumindo o papel de dirigir e registrar as reuniões, assim como de representar a associação nos seus contatos externos.

0 engajamento dos jovens rappers nas eleições municipais da cidade, acontecidas em 2000, levou a aliança entre 0 vereador e esse grupo de jovens do hip hop a um outro patamar, assim como marcou uma modificação na maneira como os jovens em foco pensavam seu futuro relacionado ao hip hop. 
Q uando, em 2000, chegou o momento das campanhas eleitorais, a relação entre rappers, dançarinos de break e grafiteiros e 0 vereador era estreita, de forma que grande parte das lideranças da Posse Rima \& Cia filiaram-se ao Partido dos Trabalhadores.

A participação de vários grupos de rap, grafiteiros e dançarinos de break na campanha do vereador implicava um reposicionamento dos laços que vinham desenvolvendo desde 1997. Ao longo desses quatro anos, esse vereador havia investido tanto na formação política quanto no suporte material desse grupo que se tornou sua base eleitoral. A relação de dependência que havia sido criada fez com que os jovens passassem a ver a sua reeleição como uma forma de garantir, material e simbolicamente, as atividades que vinham desenvolvendo com o hip hop. Atraídos pelo principal capital político do vereador, a credibilidade, aqueles que não eram filiados ao partido também assumiram sua campanha.

A percepção de que a atividade que vinham desenvolvendo no hip hop tinha uma proximidade com a militância político-partidária foi construída ao longo do tempo, especialmente no contato com militantes mais experientes: inclusive quem falava no PT pelo hip hop era o Alessandro, então ele tinha uma certa influência lá dentro, era o cara do hip hop no PT, conta.

Aos poucos, os jovens passaram a perceber-se como militantes da política partidária, engajando-se, por exemplo, nas eleições municipais.

Ao mesmo tempo, como as atividades do hip hop aglutinavam um número grande de jovens, eles passaram a ganhar visibilidade no interior do partido, pois eram percebidos como representantes de uma numerosa e visível base eleitoral. Além disso, como militantes já razoavelmente treinados pelas discussões e pela proximidade com o sindicato e com o partido político, esses jovens dominavam alguns saberes que eram necessários na militância el eitoral.

0 acúmulo de um capital militante, tal como a capacidade para mobilizar, aglutinar pessoas, redigir panfletos, criar estratégias de divulgação, já fazia parte da experiência com a Posse Rima \& Cia, favorecendo a entrada desses jovens nas atividades desenvolvidas durante as eleições. D a mesma maneira, as disposições sociais mencionadas anteriormente, ou seja, uma socialização que favorecesse ordem e disciplina e uma pulsão pela ascensão social também contribuíram para que esses jovens, ou pelo menos as lideranças, aceitassem a lógica de submissão aos valores, às hierarquias e às censuras próprias da estrutura dos partidos políticos.

Além do saber militante acumulado, dado pela formação política ao longo dos anos em que estiveram associados ao vereador, o conjunto de retribuições materiais e simbólicas garantidas pelo "mandato", assim como promessas de 
retribuições futuras, favoreceu a entrada, na campanha para as eleições municipais, de alguns dos jovens que atuavam com o vereador.

\section{Retribuição militante e a aliança entre hip hop e o PT}

A retribuição militante é um fator a ser considerado tanto na permanência do militante no partido quanto na relação desse partido com os demais na luta pela conquista do poder público.

Segundo Gaxie (1977), há três tipos de recrutamento que os partidos desenvolvem para atuar frente às eleições: (i) a contratação de agentes exteriores, ou seja, profissionais, sendo essa freqüentemente uma ação dos partidos de quadros que têm recursos financeiros; (ii) a manutenção de postos permanentes no partido, com recursos de contribuição ou do patronato; e (iii) o recrutamento de militantes, uma prática comum dos partidos de massa que, desprovidos de recursos materiais, apóiam-se em diversas estratégias de retribuição, como postos, empregos ou mesmo satisfações pessoais, relativas à integração em um grupo, à criação de rede de relações de lazer, de amizade, de matrimônio, ou mesmo ao contentamento obtido pelo devotamento a uma causa.

Enquadrando-se neste último caso, o PT de Campinas não escapa à lógica de recrutamento dos militantes para as eleições a partir de uma negociação que envolva retribuições futuras. U ma das primeiras retribuições exigidas pelas lideranças do hip hop foi 0 apoio a projetos referentes às atividades culturais em espaços públicos no centro da cidade, o que implicava uma canalização de recursos nessa direção.

No entanto, não podemos dizer que 0 engajamento na militância eleitoral se tenha dado apenas pelas retribuições materiais que o PT poderia oferecer, até porque o número de militantes era superior à quantidade de retribuições econômicas ou materiais de que o partido disporia, mesmo ganhando as eleições. Existem outras retribuições de ordem simbólica. 0 orgulho da militância devotada, que impõe uma marca pessoal, definindo o indivíduo como um sujeito diferenciado diante de alguns grupos, não deixa de ser uma forma de retribuição, assim como a própria identificação com o vereador que, de uma origem social semelhante à deles, ascendeu socialmente no campo da política?.

8. Em artigo publicado em 2005, Gaxie especifica como as retribuições do militantismo intervêm na lógica das finalidades da ação coletiva: "É em se mobilizando pela causa que os militantes retiram diversas satisfações. O investimento na causa não é um elemento independente e distinto dos interesses militantes que será invocado para os justificar e os ocultar, mas um elemento freqüentemente intrinsecamente apegado a tudo que é dado o preço ao militantismo. E são as finalidades oficiais das ações coletivas, tais que elas são percebidas por cada participante ou simpatizante, que dão sentido e valor às retribuições do militantismo" (Gaxie, 2005, p. 174). 
U ma das falas de Alessandro mostra uma identificação com o vereador e 0 orgulho que ele, Alessandro, sente das relações pessoais estabelecidas com aquele que se apresenta como igual. D a mesma maneira como o sentimento de orguIho de $M$ iro em fazer campanha e eleger seu candidato, que é a pessoa com a qual ele se identifica, demonstra que o partido, tanto quanto ou mais do que um espaço de relações propriamente ideológicas, é um locus de relações de amizade e confiança capaz de mobilizar recursos políticos.

Porém, o engajamento dos jovens do hip hop no PT durante as eleições municipais e, principalmente, a dedicação com que se empenharam na campanha, além de derivarem de questões relativas à própria lógica da luta entre os partidos pela conquista de mandatos, têm uma outra faceta: aquela referente à luta no interior do hip hop para garantir condições tanto materiais, para manter suas atividades, quanto simbólicas, para impor uma visão dominante sobre o que é militância no hip hop. Essa questão tornou-se um tanto mais premente quando a disputa no espaço do hip hop e no espaço político deu origem ao surgimento de outros pleiteantes a porta-vozes do movimento hip hop de Campinas.

Em 1997, quando o grupo de rappers que fundou a Posse Rima \& Cia se confrontava com os rappers estabelecidos na cena hip hop da cidade, um dos principais opositores com que se confrontavam era um rapper chamado $\mathrm{N}$ iasha, pouco mais velho do que eles e que já tinha uma posição consolidada no espaço de divulgação de rap, dispondo de suficiente cacife para realizar seus próprios eventos.

$\mathrm{N}$ esse período, $\mathrm{N}$ iasha já era militante do $\mathrm{PC}$ doB, tendo chegado ao partido via militância estudantil. Ao longo desses quatro anos (1997-2000), N iasha foi presidente do grêmio e da U nião Campineira de Estudantes Secundaristas (UCES), já havia escrito dois livros (um publicado independentemente e outro financiado pela União Nacional dos Estudantes - UNE), fazia um programa em uma rádio reconhecida por tocar rap (105 FM), havia participado do movimento negro e tinha sido convidado para participar de um programa televisivo da M TV como debatedor.

O PCdoB aproximou-se do hip hop, via movimento estudantil, um pouco antes que o PT, o que parece demonstrar ter sido essa uma aliança visualizada por vários partidos de esquerda no período.

A aproximação de $\mathrm{N}$ iasha com o partido político foi diferente da experimentada pelos rappers em foco, já que ele entrou no PC doB como representante do movimento estudantil e não do movimento hip hop, mesmo considerando que 0 fato de ser membro da cena hip hop da cidade o tornaria mais valioso para 0 partido: 
[...] A juventudedo PC doB era demovimento estudantil, não era dehip hop. [...] Eu só tiveforça no movimento estudantil porque eu era do hip hop, porquesenão eu ia ser maisum ali, um etudante dedassemédia, branco. Q ual era o diferencial ali, eu era oúnico cara da perifa, do hip hop, no meio ali, então oscaras... Porque não tinha isso, porqueo movimento estudantil era praticamente, nosanos 90 , dassemédia, colégio central, vocênão via muita gente do outro lado delá. [...] Eu formé um grupo comigo, um timemeu, queacabou seaproximando ao PC doB. (N iasha, Entrevista de pesquisa, Campinas, junho 2006).

Q uando, em 2000, chegou o momento em que se intensificou a campanha pelas eleições municipais, N iasha, que atuava com o setor "juventude" do partido, no qual era uma das principais lideranças, lançou-se como candidato a vereador pelo PC doB e montou uma associação com o nome de Força Cultural H ip H op para a campanha.

0 depoimento do rapper que ficou à frente da associação e da campanha de $\mathrm{N}$ iasha revela que a Força Cultural H ip H op, além de ter sido montada objetivamente para a campanha de $\mathrm{N}$ iasha, estava orientada para opor-se à Posse Rima \& Cia que, em 2000, já era reconhecida como o grupo do hip hop do PT.

Os dois grupos, que até ali disputavam espaço na divulgação do rap e dos eventos de hip hop, passaram a enfrentar-se também no campo da disputa eleitoral, pleiteando tanto o status de representantes do movimento hip hop que, com isso, ajudaram a construir, quanto a maior antiguidade na relação com a política partidária.

Em virtude da fragilidade de ambos os grupos do hip hop, dependentes dos partidos políticos para efetivarem suas práticas, a disputa era acirrada, impulsionando os grupos a mobilizar discursos diferentes sobre o hip hop. Ao mesmo tempo, no entanto, essa disputa criou uma relação de interdependência entre os grupos, de forma que um legitimava a posição do outro diante dos praticantes do hip hop que afirmavam representar e diante dos políticos profissionais. As críticas, as maledicências, as acusações não foram economizadas: manifestaram-se como formas de categorização e explicitação das lutas, objetivando, pela nomeação, posições e visões de mundo distintas e concorrentes. N o meio tempo, ambos os grupos levaram conjuntos de rap para e apresentar-se nos comícios de um e de outro partido.

Como uma forma de aglutinar jovens do hip hop para suas campanhas, tanto o vereador que apoiava a Posse Rima \& Cia, quanto Niasha, financiado pela U nião da Juventude Socialista (UJS), ligada ao PC doB, bancaram e organizaram, em 2000, a gravação de CD s de grupos que os apoiavam. 
N esse mesmo ano, o PT e o PC doB não se coligaram para a campanha eleitoral municipal - um resultado movido, pelo menos em parte, pela rivalidade dos vereadores que se apresentavam como porta-vozes de movimentos sindicais e do hip hop, como relataram militantes entrevistados para esta pesquisa.

Ao final, o resultado foi favorável aos militantes da Posse Rima $\&$ Cia e aos dançarinos de break e grafiteiros que atuavam junto com o grupo, pois o candidato do PT venceu as eleições para prefeito da cidade; o vereador a que estavam ligados também se reelegeu, tendo sido o nono vereador mais votado da cidade, com 7.694 votos, vindo a tornar-se depois presidente da Câmara M unicipal. N iasha não conseguiu se eleger para o cargo de vereador, mas conseguiu 3.138 votos e saiu como suplente em $32^{\circ}$ lugar.

0 resultado das eleições alterou as demandas e a atuação dos jovens rappers da Posse Rima \& Cia, da União dos Grafiteiros e dos dançarinos de break que atuavam junto com eles. Com a entrada do PT no poder, esses jovens passaram a lutar pela inserção do hip hop como alvo de políticas públicas, cobrando as promessas de retribuição feitas tanto pelo vereador quanto pelo próprio candidato a prefeito durante a campanha. Em 2001, ao final de um longo processo, seus membros conseguiram o apoio da prefeitura municipal da cidade, assumida pelo PT naquele ano, para a criação da Casa do H ip Hop de Campinas, onde as principais lideranças da associação foram alocadas como funcionários, em diferentes níveis salariais e de responsabilidade.

Entre 2002 e 2004, a C asa funcionou como um espaço de discussão e desenvolvimento de atividades do hip hop, aglutinando artistas e estabelecendo uma proposta de formação nas artes do hip hop. Foi desativada pelo novo prefeito eleito pelo PDT, apoiado por uma coligação em que se incluíra o PC doB. $\mathrm{D}$ epois de permanecer fechada por quase três anos, esse prefeito autorizou sua reabertura em 2006, sob a coordenação de N iasha.

\section{Considerações finais}

Sem pretender retomar 0 argumento desenvolvido neste texto em todas suas minúcias, achamos importante frisar este aspecto essencial sobre as organizações militantes, que nem sempre é suficientemente levado em consideração: seu surgimento não é uma obra do acaso nem pode ser explicado apenas pela pulsão de seus membros.

Ao contrário, como a pesquisa sobre os jovens militantes do movimento hip hop de Campinas permitiu mostrar, a transformação de atitudes e disposições para o protesto em ações efetivas de intervenção organizada no espaço político não está disponível para qualquer um, mas é, antes, o resultado de um trabalho 
minucioso que os profissionais da política tomam como sua responsabilidade incentivar.

A nosso ver, esse tipo de estudo oferece a possibilidade de compreender com maior precisão tanto o trabalho, muitas vezes oculto, de transmissão e socialização política que as velhas gerações desempenham com relação às mais novas, quanto a força das relações estabelecidas como retribuição militante para a sobrevivência das alianças.

\section{Referências bibliográficas}

AN D RADE, Elaine $N$ unes de. M ovimento negro juvenil: um estudo de caso sobre jovens rappers deSão Bernardo do Campo. 1996. D issertação (M estrado) - FaculdadedeE ducação, USP, São Paulo.

AN D RAD E, ElaineN unes de (O rg.). Rap eeducação, rap éeducação. São Paulo: Selo N egro, 1999.

BERRY, Jeffrey M . Citizen groups and the changing nature of interest group politics in America. Annals of the American Academy of Political and Social Sciences, v. 521 Citizens, Protest, and D emocracy, p. 30-41, 1993.

BO U RD IEU , Pierre. Espaço social e gênese das classes. 0 poder simbólico. Rio de Janeiro: Bertrand Brasil, 2000a. p. 133-154.

EDITO RIAL. Improviso - Informativo do M ovimento Hip H op. Campinas, n. 1, nov. 2003.

FÉLIX, J. B. J. Chic show eZimbabweea construção da identidadenosbailesblackspaulistanos D issertação (M estrado) - FaculdadedeFilosofia, Letrase Ciências H umanas, U SP, São Paulo, 2000.

GAXIE, D aniel. Économie des partis et retribuitions du militantisme. Revue F rançaise de SciencePolitique, n. 27, p. 123-154, fév. 1977.

GAXIE, D aniel. Rétribution du militantismeet paradoxes del'action collective. RevueSuissede SciencePolitique, v. 11, p. 157-188, Spring 2005.

GU ASCO , Pedro Paulo M . N um paíschamado periferia: identidadeerepresentação da realidade entre os rappers de São Paulo. 2001. D issertação (M estrado) - Departamento de Antropologia,USP, São Paulo.

GU ILLOT, Philippe. Introduction à la sociologiepolitique Paris: Armand Colin, 1998.

H ERSC H M AN N , M icael. Abalando osanos90: funk ehip hop. Rio deJ aneiro: Rocco, 1997.

LI M A, M ariana Semião de. 0 rap debatom: família, educação egênero no rap. D issertação (M estrado) - Faculdade deEducação, Unicamp, C ampinas, 2005.

M cFARLAN D , Andrew S. Interest groupsand political time: cyclesin America. British J ournal of Political Science, v. 21, n. 3, p. 257-284, 1991. 
M OREN O, Rosangela C arrilo. As mutações da experiência militante: um estudo a partir do movimento de Campinas. Dissertação (M estrado) - Faculdade de Educação, Unicamp, Campinas, 2007.

M OREN O, Rosangela; ALM EID A, Ana M aria F. 0 engajamento político dos jovens no movimento hip hop. Revista Brasileira deE ducação, n. 40, jan.-abr. 2009.

OFFERLÉ, M ichel. Les partispolitiques Paris: Presses U niversitaires deFrance, 1987. Coll. "Q uesaisje?".

OFFERLÉ, M ichel. Sociologiedesgroupesd'intérêt. Paris: M ontchrestien, 1998.

OFFERLÉ, M ichel. La profession politique- XIX et XX siécles, Paris: Belin, 1999.

O FFERLÉ, M ichel. Un homme, unevoix? H istoire du suffrage universel. Paris: Gallimard, 2002 [1993].

SAW ICKI, Fréderic. Les temps de l'engagement: à propos de l'institutionnalisation d'une association de défense de l'environnement. In : LAG ROYE, Jacques. La politisation, Paris: Belin, 2003.

TRU M AN , D avid B. Thegovernmental process. N ew York: Knopf, 1951.

Recebido em 31 deoutubro de 2008 eaprovado em 06 demarço de 2009. 